\title{
Demand Systems With Nonstationary Prices
}

\author{
Arthur Lewbel* $\quad$ Serena $\mathrm{Ng}$
}

December 1999

Revised June 2002

\begin{abstract}
Relative prices are nonstationary and standard root- $T$ inference is invalid for demand systems. But demand systems are nonlinear functions of relative prices, and standard methods for dealing with nonstationarity in linear models cannot be used. Demand system residuals are also frequently found to be highly persistent, further complicating estimation and inference. We propose a variant of the Translog demand system, the NTLOG, and an associated estimator that can be applied in the presence of nonstationary prices with possibly nonstationary errors. The errors in the NTLOG can be interpreted as random utility parameters. The estimates have classical root- $T$ limiting distributions. We also propose an explanation for the observed nonstationarity of aggregate demand errors, based on aggregation of consumers with heterogeneous preferences in a slowly changing population. Estimates using US data are provided.
\end{abstract}

Keywords: Demand Systems, Nonstationarity, Aggregation, Heterogeneity, Fixed Effects, Translog, Inflation.

${ }^{*}$ This research was supported in part by the National Science Foundation through grant SES-9905010. We would like to thank Jean-Marc Robin for helpful discussions. All errors are our own.

Serena Ng: Dept. of Economics, Johns Hopkins University, Baltimore, MD 21218, serena.ng@jhu.edu Corresponding Author: Arthur Lewbel, Department of Economics, Boston College, 140 Commonwealth Ave., Chestnut Hill, MA, 02467, USA. (617)-552-3678, lewbel@bc.edu 


\section{Introduction}

In most industrialized economies real per capita income trends upward and inflation rates are positive. More precisely, the tendency for prices and standards of living to rise makes the time series of prices and real income nonstationary. Less obviously, relative prices are also nonstationary (see, e.g., Ng 1995 and Lewbel 1996b). This is recognized informally in the observation that the prices of some goods, such as higher education and medical care, have been rising significantly faster than the average rate of inflation for many years. More broadly, debates over which price measure to use to index social security or to assess monetary policy are based on the fact that different measures diverge over time, which could only occur if there are differences in growth rates of the prices of different goods.

Almost every empirical demand system study suffers from a severe econometric flaw, namely, failure to cope with this nonstationarity of prices $^{1}$. The usual techniques for handling nonstationary regressors, such as cointegration or linear error correction models, cannot be applied to demand system estimation because any nontrivial demand system that is consistent with utility maximization must be nonlinear in relative prices (see section 4 below). But very few estimators exist for nonlinear structural models of any form containing nonstationary data. The problem is further exacerbated by the facts that demands are multiple equation systems with nonlinear cross equation restrictions mandated by utility maximization, and that demand systems with dimensions large enough to be empirically interesting involve a large number of parameters relative to the number of available time periods $T$. These problems affect demand systems estimated using individual, household, panel, cohort, or aggregate level data, since all depend upon utility maximizing agents facing nonstationary relative prices $^{2}$.

Because of these many difficulties, existing demand system studies either ignore the problem entirely, or deal with nonstationarity using linear model cointegration methods ${ }^{3}$. Even if one could overcome the problems of nonlinearity and high dimension, cointegration methods may still not be appropriate because the errors in demand systems (particularly

\footnotetext{
${ }^{1}$ See, e.g., Stock (1994) and Watson (1994) for a review of econometric issues relating to nonstationary variables.

${ }^{2}$ Other issues, including the lack of variation in prices, arise with estimation using cross-section data.

${ }^{3}$ For example, Attfield (1997), applies linear cointegration techniques to Deaton and Muellbauer's (1980) Almost Ideal model, replacing the true nonlinear (quadratic) price deflator terms with an approximate linear index. Ogaki (1992) employs a two good demand systems along with a functional form that restricts cross price effects to obtain a linear model for cointegration. Adda and Robin (1996) provide conditions for unbiased multiple cross section demand system estimates with nonstationary prices, but they also assume a linear model.
} 
those estimated with aggregate data) tend to be highly autocorrelated ${ }^{4}$. As is well known, standard asymptotic theory provides a poor guide to finite sample inference when the errors are highly persistent. In cases when a unit root in the residuals cannot be rejected, the regressions are spurious and the parameter estimates are inconsistent.

In this paper, we provide a novel solution to the problem of estimating utility derived demand systems with nonstationary prices. The methodology is also robust to the possibility of nonstationary model errors. The key is a new functional form that, by interacting budget shares with prices, produces a model that is both consistent with utility maximization and when differenced, enables non-linear estimation of the demand parameters by instrumental variables. Classical root-T consistency and asymptotic normality of the estimates then follows from Hansen's (1992) theory for GMM (the Generalized Method of Moments). The model, which we call NTLOG (nonstationary Translog), is a variant of Jorgenson, Lau, and Stoker's (1983) Translog demand system. Unlike the Translog system in which the errors are appended to budget shares, the error term in the aggregate NTLOG model takes the form of an average random utility parameter. As such, persistence in the error of the aggregate model can be attributed to preferences in a slowly changing heterogeneous population.

Our NTLOG model and the associated estimator provides a solution to the generic empirical problem of demand system estimation with nonstationary relative prices, regardless of the source (or even existence) of persistence in the errors. We apply it to aggregate data, but it could also be applied using data at the level of cohorts or individual households, which also suffer from the same nonstationarity of relative prices.

The plan of this paper is as follows. In the next section, we use United States demand data to provide additional evidence of nonstationarity of demand system regressors. We also show that nonstationarity in the residuals is not due simply to missing variables. In section 3 we propose a possible explanation for these nonstationary errors, by showing that error persistence could arise as the result of aggregation across utility maximizing individuals with heterogeneous preferences in a slowly changing population. We later provide empirical evidence that this explanation is at least plausible using household level data on food demand from the Michigan PSID surveys. Sections 4 and 5 of the paper give the derivation of the NTLOG functional form. Section 6 provides our estimator of this NTLOG model and the associated empirical results, and section 7 is conclusions.

\footnotetext{
${ }^{4}$ See, e.g., Berndt and Savin (1975), Stoker (1986), Lewbel (1991,1996a), and Pollak and Wales (1992).
} 


\section{Nonstationary Demands, Prices, and Incomes}

We begin in this section with an exploratory empirical analysis of United States demand data, documenting nonstationarity of regressors and a high degree of persistence in demand model residuals. We also provide evidence that residual nonstationarity is not due to omitted variables.

Let $p_{i t}$ be the price of good or service (or group of goods and services) $i$ in time $t$, $i=1, \ldots N$, and $t=1, \ldots T$. Let $M_{t}$ be per capita expenditures on goods and services in time $t, W_{i t}$ be the fraction of $M_{t}$ spent on group $i$ in time $t$, and let $r_{i t}=\ln \left(p_{i t} / M_{t}\right)$. By homogeneity (the absence of money illusion), demands are functions of $r_{t}$, the vector of elements $r_{i t}$. Figures 1 and 2 present graphs of log prices and $r_{i t}$ for four groups of nondurable goods and services:- food (Good 1), energy (Good 2), clothing (Good 3), and all other non-durable goods and services (Good 4). Even after taking logarithms, the graphs clearly show the drifts and trends of nonstationary behavior. Similar results are obtained when deflating by an overall price index like the CPI instead of $M_{t}$. Figure 3 shows the corresponding graph for aggregate budget shares $W_{i t}$, indicating that at least some of these shares may also appear nonstationary. Budget shares must by construction lie between zero and one, and so cannot remain nonstationary forever, but as long as the magnitude of changes from year to year are small (relative to the range zero to one), shares can closely approximate a nonstationary process for decades, as may be the case for some shares in this US data.

Results of formal tests of nonstationarity using the DFGLS test of Elliot, Rothenberg and Stock (1996) and the MZGLS test of Ng and Perron (2001) are summarized in Table $1 .{ }^{5}$ For a system of four goods, we consider log prices, log normalized prices, total expenditure, budget shares, and some cross terms for a total of 39 variables over the period 1954-1998. Both tests cannot reject the null hypothesis of a unit root around a linear trend. ${ }^{6}$ However, when the first difference of each series is tested for a unit root, the tests reject nonstationarity in 38 of the 39 series being tested. Prices $r_{t}$ are faced by all consumers, so estimates of demand equations at any level of aggregation or disaggregation will need to deal with nonstationarity of prices.

\footnotetext{
${ }^{5}$ The DFGLS and the MZGLS estimate the trend parameters more efficiently and are more powerful than the Dickey-Fuller (DF) test and the modified Phillips-Perron $M Z$ tests of Perron and Ng (1996). The MZ tests have better size properties than the Phillips-Perron $Z$ tests. Results are reported for $M Z_{\alpha}$ and $M Z G L S_{\alpha}$, which are improved versions of $Z_{\alpha}$.

${ }^{6}$ The lag lengths of the augmented autoregressions are selected by the MAIC developed in Ng and Perron (2001). The BIC (not reported) leads to the same conclusion that the level of the series are not stationary.
} 
While our later estimates will permit budget shares to be stationary, assume for now that budget shares and logged scale prices are $I(1)$, as indicated by the tests in Table 1 . In that case, linear in $r$ demand equations

$$
W_{i t}=a_{0 i}+a_{1 i} t+b_{i}^{\prime} r_{t}+e_{i t}
$$

could be consistently estimated by standard least squares methods if the errors $e_{i t}$ in equation (1) are stationary. Stationary errors for these equations would require that $W_{i t}$ and $r_{t}$ be cointegrated for each commodity group $i$. To test for cointegration, we include a deterministic time trend in (1) as linear trends are found to be significant in e.g., Banks, Blundell, and Lewbel (1997). Tests for the null hypothesis of no cointegration in Table 2 indicate that these errors are not stationary (and remain nonstationary even when a quadratic trend is included as a regressor). We use two variants of the residuals based cointegration test developed in Phillips and Ouliaris (1991). The $5 \%$ critical value with four regressors and a linear trend is -4.49 for the Dickey-Fuller $D F$ test, and -37.7 for the modified Phillips-Perron test $\left(M Z_{\alpha}\right)$. For three of the four consumption groups, the evidence of no cointegration is overwhelming. In the case of clothing, the DF test is -4.885 and rejects a unit root in $e_{i t}$ but the $M Z_{\alpha}$ test is -31.804 and does not reject the null hypothesis of no-cointegration.

We might not expect cointegration in (1), because utility maximization, and in particular, Slutsky symmetry, would impose implausibly strong cross equation restrictions on the coefficients (see section 4 below). A much more reasonable class of demand equations is

$$
W_{i t}=a_{0 i}+a_{1 i} t+b_{i}^{\prime} r_{t}+c_{i} g\left(x_{t}\right)+e_{i t}
$$

where $g\left(x_{t}\right)$ is some function that is common to all of the demand equations and $x_{t}$ is a vector of observed or unobserved variables (which could include $t$ and $r_{t}$ ) that affect demand. In particular, one of the most frequently employed demand systems in empirical work, Deaton and Muellbauer's (1980) Almost Ideal Demand System (AIDS), is a special case of (2) in which $g$ is a constrained quadratic in $t$ and $r_{t}$. We tested for cointegration in the approximate AIDS model, which uses Stone's price index $\left(P^{*}\right)$ to deflate total expenditure, as is common practice in this literature (see, e.g., Deaton and Muellbauer 1980). This amounts to using $g\left(x_{t}\right)=-\sum_{j=1}^{N} w_{j t} r_{j t}$ in (2). The results are given in the second panel of Table 2. The critical values for the two tests with five regressors are -4.74 and -42.5 respectively. Once again, there is strong evidence for non-cointegration in three of the four cases, with clothing being the possible exception. ${ }^{7}$

\footnotetext{
${ }^{7}$ Formally, if both $w_{j t}$ and $r_{j t}$ are $I(1)$ then $\sum_{j=1}^{N} w_{j t} r_{j t}$ would generally be $I(2)$, however, this sum
} 
Having equation (2) hold for every group $i$ implies that

$$
W_{i t}=\widetilde{a}_{i}+\widetilde{a}_{1 i} t+\widetilde{b}_{i}^{\prime} r_{t}+\widetilde{c}_{i} W_{1 t}+\widetilde{e}_{i t}
$$

where $\widetilde{e}_{i t}=e_{i t}-e_{1 t} / c_{1}$. Therefore, if the errors $e_{i t}$ in equation (2) were stationary, then the errors $\widetilde{e}_{i t}$ in (3) would also be stationary. This means that a necessary condition for the AIDS model, or for any other demand equation in the form of equation (2), to have well behaved (i.e., stationary) errors is that $W_{i t}, r_{t}$, and $W_{j t}$ must be cointegrated for each group $i \neq j$. However, the test statistics in Table 3 indicate that $W_{i t}, r_{t}$, and $W_{j t}$ (for any $j \neq i$ ) are not cointegrated, and hence any model in the form of equation (2), including the exact AIDS model, will yield inconsistent parameter estimates.

More generally, the test results based on equation (3) show that failure of cointegration is not due to any single missing variable or regressor. This is because utility maximization would require that any omitted variable appear in the demand equations for all goods $i$. Cointegration of (2) with any variable or function $g\left(x_{t}\right)$ would imply cointegration of equation (3), which is rejected.

An even more general class of demand systems is

$$
W_{i t}=a_{0 i}+a_{1 i} t+b_{i}^{\prime} r_{t}+c_{1 i} g\left(x_{t}\right)+c_{2 i} g_{2}\left(x_{t}\right)+e_{i t}
$$

for arbitrary functions $g\left(x_{t}\right)$ and $g_{2}\left(x_{t}\right)$. Examples are the approximate QUAIDS (quadratic AIDS) model of Blundell, Pashardes, and Weber (1995) and the exact, integrable QUAIDS model of Banks, Blundell, and Lewbel (1997). Panel 3 of Table 2 reports cointegration tests for (4), taking $g$ to be log deflated income, and $g_{2}=g^{2}$, corresponding to the approximate QUAIDS model. ${ }^{8}$ In all cases, $M Z_{\alpha}$ is less than the approximate critical value of -47.5 . The approximate critical value for the DF is -5.05 . Again, clothing is the only good for which there is some support for cointegration.

Similar to (3), having equation (4) hold for every group $i$ implies that

$$
W_{i t}=\widetilde{a}_{i}+\widetilde{a}_{1 i} t+\widetilde{b}_{i}^{\prime} r_{t}+\widetilde{c}_{1 i} W_{1 t}+\widetilde{c}_{2 i} W_{2 t}+\widetilde{e}_{i t}
$$

where $\widetilde{e}_{i t}$ is linear in $e_{i t}, e_{1 t}$, and $e_{2 t}$. Therefore, if the errors $e_{i t}$ in equation (4) were stationary, then the errors $\widetilde{e}_{i t}$ in (5) would also be stationary, so a necessary condition for any demand

appears to be $I(1)$ in this data. This could be due to the fact that the trends in $w_{j t}$ are far less pronounced than those in $r_{j t}$, and it is possible that $w_{j t} r_{j t}$ for $j=1, \ldots, N$ are close to cointegrated, resulting in a sum that is $I(1)$ instead of $I(2)$.

${ }^{8}$ Exact critical values have not been tabulated for systems of such high dimensions. $\mathrm{Ng}$ (1993) finds that an approximate guide is to raise the critical value of the DF by 0.35 , and the $M Z_{\alpha}$ by 5 , for each added regressor. 
equation in the form of equation (5) to have stationary errors is that $W_{i t}, r_{t}, W_{j t}$ and $W_{k t}$ be cointegrated for each group $i \neq j, k$. As with all the other models tested, the test statistics in the second panel of Table 3 indicate that $W_{i t}, r_{t}, W_{j t}$ and $W_{k t}$ (for any ordering of the goods) are not cointegrated.

Analogous to the discussion regarding equation (3), failure of cointegration of equation (5) implies that nonstationarity of the demand system errors could not be due to any two missing regressors. Other evidence of nonstationarity is provided by $\mathrm{Ng}$ (1995), Lewbel (1996), and Attfield (1997). We will later give one more example of demands that are linear in variables, based on the Translog system, and show that it too appears to have nonstationary errors.

The test statistics used in this section are based on asymptotic theory assuming $T$ is extremely large, and also that $T$ is large relative to the number of regressors, which is not the case here. The small sample distortions in some of these tests could therefore be substantial. Nevertheless, the evidence of trends or drifts in relative prices, aggregate total expenditures, and aggregate demand system errors seems strong, even if exact $p$ values for many of these tests might be in doubt.

\section{Aggregation and Nonstationary Errors}

In this section, we propose one possible explanation for the empirically observed high autocorrelation and possible nonstationarity of aggregate demand system errors. We show that this persistence could be caused by aggregation across a slowly changing population of consumers with heterogeneous preferences. Our NTLOG model does not depend on the validity of this explanation, and in fact can be applied to deal with nonstationary prices even if the demand system errors are stationary, but it is useful to understand why demand errors could be persistent.

Blundell, Pashardes, and Weber (1993) suggest that aggregation over consumers with time varying individual specific effects can lead to omitted variations in the aggregate demand system. Here, we show that even if the individuals have specific effects that are time invariant, aggregating over an evolving population with heterogeneous preferences will induce omitted variations (i.e., aggregate errors). Moreover, since the population evolves slowly over time, these omitted effects are likely to be highly persistent.

To see how aggregation across consumers could cause persistence in aggregate demand system errors, let $a_{h i}$ be a fixed effect of consumer $h$ for good $i$. This fixed effect can be interpreted as a taste parameter, that is, a parameter in consumer $h$ 's utility function. Let $\mathcal{H}_{t}$ be the set of all consumers in the economy in time $t$, and $H_{t}=\sum_{h \in \mathcal{H}_{t}} 1$ be the enumeration 
of $\mathcal{H}_{t}$. Note that $\mathcal{H}_{t}=\mathcal{H}_{t-1}+\mathcal{H}_{t}^{+}-\mathcal{H}_{t-1}^{-}$, where $\mathcal{H}_{t}^{+}$is the set of consumers who enter the economy in period $t$, and $\mathcal{H}_{t-1}^{-}$is the set of consumers that leave the economy in period $t-1$. Then $a_{i t}=\frac{1}{H_{t}} \sum_{h \in \mathcal{H}_{t}} a_{h i}$ is the simple average of $a_{h i}$ across the consumers. We can write

$$
\begin{aligned}
a_{i t} & =\frac{H_{t-1}}{H_{t}} a_{i t-1}+\frac{\sum_{h \in \mathcal{H}_{t}^{+}} a_{h i}-\sum_{h \in \mathcal{H}_{t-1}^{-}} a_{h i}}{H_{t}}, \\
& =\nu_{t} a_{i t-1}+\eta_{i t},
\end{aligned}
$$

where $\nu_{t}$ is the relative size of the population between the two periods, and $\eta_{i t}$ is the average difference between the preferences of the consumers that dropped out and those that were added in time $t$. The dynamic properties of $a_{i t}$ thus depend on $\nu_{t}$ and $\eta_{i t}$. Consider first the latter. Taste parameters $a_{h i}$ depend in part on age, family size, and other demographic characteristics. All these variables change slowly over time. Also, to the extent that taste parameters vary across households and cohorts, the average taste parameter of those who drop out will generally differ from the average taste parameter of those who enter the sample in any given period. Both considerations suggest that $\eta_{i t}$ should exhibit random variations.

Now $\nu_{t}$ depends on the number of consumers in two consecutive periods and does not depend on $i$. Since the set of consumers in an economy changes slowly over time, the large majority of consumers comprising $\mathcal{H}_{t}$ are also in $\mathcal{H}_{t-1}$. If $\eta_{i t}$ is uncorrelated with $a_{i t-1}$, then this implies that $a_{i t}$ is a highly persistent, near unit root process. More generally, $\eta_{i t}$ can be correlated with $a_{i t-1}$, which could increase or decrease the persistence in $a_{i t}$. In postwar quarterly data, $\nu_{t}$ ranged from a low of 0.9921 to a high of 0.9982 with a standard deviation of 0.0009 , so empirically $\nu_{t}$ is very close (but not exactly equal) to one.

Whether $a_{i t}$ is a near unit root process or not depends on both on the evolution of the population $\mathcal{H}_{t-1}$ and the distribution of the demand system errors $a_{h i}$ in each time period. These are not directly observed, but we will later provide empirical evidence that substantial persistence in $a_{i t}$ is at least plausible, based on an analysis of food demand at the household level using PSID data.

The above argument for persistence in the average fixed effect assumes that each household receives the same weight of $1 / H_{t}$, but the argument also holds when $a_{i t}$ is defined as an unequally weighted average. Let $\omega_{h t}$ be the weight applied to household $h$ at time $t$. Then for $a_{i t}=\sum_{h \in \mathcal{H}_{t}} \omega_{i h t} a_{i h t}$, it can be shown that

$$
a_{i t}=\nu_{t} a_{i t-1}+\eta_{i t}+\left[\sum_{h \in \mathcal{H}_{t}}\left(\omega_{h t}-\frac{1}{H_{t}}\right) a_{h i}\right]-\nu_{t}\left[\sum_{h \in \mathcal{H}_{t-1}}\left(\omega_{h t-1}-\frac{1}{H_{t-1}}\right) a_{h i}\right]
$$


In addition to heterogeneous preferences, time variations in weights (the last two terms) will also introduce randomness into $a_{i t}$. If the weights $\omega_{h t}$ are budget shares, then the changes in the income distribution between periods will be the additional source of randomness. In consequence, one would still expect $a_{i t}$ to be an autoregressive process with a root very close to unity.

More generally, a fixed effect can be the sum of an aggregate component which is unaffected by aggregation over households (e.g., common trends in tastes), and a household specific component. Then the aggregate fixed effect, $\alpha_{i t}$, is

$$
\alpha_{i t}=a_{i 0}+a_{i 1} t+a_{i t}
$$

The implications of a slowly increasing but heterogeneous population for the aggregate fixed effect are threefold. First, a model which approximates $\alpha_{i t}$ by a deterministic trend function $a_{i 0}+a_{i 1} t$ will have omitted the random variations $a_{i t}$. Second, given the size of $\nu_{t}$ in the data, the aggregate fixed effect is likely to be well approximated by a random walk with drift. The magnitude of $\nu_{t}$ also implies that even if we were to observe $\alpha_{i t}$, unit root tests will have very low power in rejecting the null hypothesis of nonstationarity. Third, when demand system errors have autoregressive roots so close to the unit circle, the distribution of the estimated parameters will not be well approximated by the normal distribution even asymptotically, and hence standard inference will be inaccurate (this is in addition to the problems stemming from nonstationary prices). Persistence arising from time aggregation of fixed effects is consistent with the empirical evidence of nonstationarity and non-cointegration documented in the previous section, and with the high degree of serial correlation found in the errors of estimated demand systems cited in the introduction.

\section{A Linear Form for Translog Demands}

In the time series literature, nonstationarity is readily handled in the context of linear models. The difficulty for demand systems is that in linear models the Slutsky symmetry implied by utility maximization results in extremely restrictive and implausible constraints on cross price elasticities. Linear models are also resoundingly rejected empirically.

To illustrate the problem, suppose the demands of an individual household were given by the general linear model $w_{i t}=a_{i}+\sum_{j=1}^{N} b_{i j} \ln p_{j t}+c_{i} \ln m_{t}$, for goods $i=1, \ldots, N$, where $m_{t}$ is the consumer's total expenditures on goods and services in time $t$, and $w_{i t}$ is the fraction of $m_{t}$ spent on good $i$ in time $t$. To be consistent with utility maximization, this demand model

must satisfy homogeneity and Slutsky symmetry. Homogeneity requires $c_{i}=-\sum_{j=1}^{N} b_{i j}$ for 
$i=1, \ldots, N$, which is not overly restrictive. However, it can be directly verified that Slutsky symmetry requires either $c_{i}=0$ for all goods $i$, implying homothetic demands (budget shares independent of the total expenditure level), or it requires that $a_{i}=0$ and $b_{i j}=\beta_{i} \beta_{j}$ for some scalars $\beta_{1}, \ldots, \beta_{N}$, so that all cross price elasticities are forced to be proportional to own price elasticities. Virtually all empirical demand studies very strongly reject these restrictions.

Similar restrictions arise in linear models expressed in terms of quantities rather than budget shares, as observed by Deaton (1975), who raised these objections in the context of the Stone-Geary Linear Expenditure System. This is why the Linear Expenditure System is now rarely used for empirical applications. For the same reason, the Rotterdam model (see Barten 1967 and Theil 1971), which is a linear demand system based on time differencing of quantities and prices, has been abandoned for empirical work.

To see how we construct a model that is linear in variables while overcoming these constraints, consider the Translog indirect utility function of Christensen, Jorgenson, and Lau (1975),

$$
U\left(p_{t}, m_{t}\right)=\sum_{i=1}^{N}\left(\alpha_{i}+\frac{1}{2} \sum_{j=1}^{N} b_{i j} \ln \frac{p_{j t}}{m_{t}}\right) \ln \frac{p_{i t}}{m_{t}} .
$$

The function $U$ here denotes the indirect utility function for the household. Without loss of generality, assume $\sum_{i=1}^{N} \alpha_{i}=1$ and $b_{i j}=b_{j i}$. Define $c_{i}=\sum_{j=1}^{N} b_{i j}$ with $\sum_{i=1}^{N} c_{i}=0$ to make the translog exactly aggregable, see Muellbauer (1975), Jorgenson, Lau, and Stoker (1983) and Lewbel (1987). By Roy's identity, the resulting Translog budget shares are

$$
w_{i t}=\frac{\alpha_{i}+\sum_{j=1}^{N} b_{i j} \ln p_{j t}-c_{i} \ln m_{t}}{1+\sum_{j=1}^{N} c_{j} \ln p_{j t}} .
$$

Unlike the severe restrictions on elasticities implied by linear models, equation (8) satisfies Slutsky symmetry and homogeneity without constraints on own price, cross price, or total expenditure elasticities at a point. This feature of unrestricted elasticities at a point is known as Diewert (1974) flexibility, and was one of the motivations for the derivation of both the popular Translog and Almost Ideal Demand model. Diewert and Wales (1987) show that imposing negative definiteness on the Translog does limit its flexibility at some points (see also Moschini 1999), but the resulting constraints on elasticities are minimal compared to the above described constraints required of linear models.

Now observe that equation (8) can be rewritten as

$$
w_{i t}=\alpha_{i}+\sum_{j=1}^{N} b_{i j} \ln \left(p_{j t} / m_{t}\right)-\sum_{j=1}^{N} c_{j} w_{i t} \ln p_{j t} .
$$


Equation (9) is a model for a single household, but can be readily extended to a panel of households by adding appropriate household $h$ subscripts. The relevant point for estimation is that equation (9) is linear in variables $\ln \left(p_{j t} / m_{t}\right)$ and $w_{i t} \ln p_{j t}$ for $j=1, \ldots, N$. Hence if some or all of these variables (in particular, log prices) are nonstationary, the model is at least in principle amenable to estimation using time series methods. Furthermore, $\alpha_{i}$ could be random, implying that if we were to estimate (9) in the cross-section, the errors could be interpreted as random utility function parameters. The next section provides details for our particular estimation method in the context of an aggregate version of this model.

\section{The Nonstationary Translog Demand System}

A convenient implication of the linearity of equation (9) is that it facilitates aggregation across households (for estimation with household level data, the aggregation step below can be ignored). Let $m_{h t}$ be consumer (or household) $h$ 's total expenditures on goods and services in time $t, w_{h i t}$ is the fraction of $m_{h t}$ spent on goods $i$ in time $t$, and $r_{h i t}=\ln \left(p_{i t} / m_{h t}\right)$. Also, for each good $i$ let $\alpha_{h i}$ denote the value of the parameter $\alpha_{i}$ for household $h$, so the vector of utility function parameters $\left(\alpha_{h 1}, \ldots \alpha_{h N}\right)$ embody preference heterogeneity. The household level Translog budget shares from equation (8) are

$$
w_{h i t}=\frac{\alpha_{h i}+\sum_{j=1}^{N} b_{i j} \ln p_{j t}-c_{i} \ln m_{h t}}{1+\sum_{j=1}^{N} c_{j} \ln p_{j t}} .
$$

Let $M_{t}=\frac{1}{H_{t}} \sum_{h \in \mathcal{H}_{t}} m_{h t}, W_{i t}=\frac{\sum_{h \in \mathcal{H}_{t}} w_{h i t} m_{h t}}{\sum_{h \in \mathcal{H}_{t}} m_{h t}}$, and $\delta_{t}=\frac{\sum_{h \in \mathcal{H}_{t}} m_{h t} \ln m_{h t}}{\sum_{h \in \mathcal{H}_{t}} m_{h t}}-\ln M_{t}$. Then

$$
\begin{aligned}
\widetilde{a}_{i t} & =\frac{\sum_{h \in \mathcal{H}_{t}} \alpha_{h i} m_{h t}}{\sum_{h \in \mathcal{H}_{t}} m_{h t}}-c_{i} \delta_{t}, \\
& \equiv \alpha_{i t}-c_{i} \delta_{t} .
\end{aligned}
$$

Notice that $\alpha_{i t}$ is the average fixed effect for good $i$ using expenditure shares as weights. It then follows that aggregate budget shares are given by

$$
\begin{aligned}
W_{i t} & =\frac{\widetilde{a}_{i t}+\sum_{j=1}^{N} b_{i j} \ln p_{j t}-c_{i} \ln M_{t}}{1+\sum_{j=1}^{N} c_{j} \ln p_{j t}}, \\
& \equiv \frac{\widetilde{a}_{i t}+\sum_{j=1}^{N} b_{i j} r_{j t}}{1+\sum_{j=1}^{N} c_{j} \ln p_{j t}},
\end{aligned}
$$

since $r_{i t}=\ln \left(p_{i t} / M_{t}\right)$. Models like this aggregate translog would usually be estimated as in Jorgenson, Lau, and Stoker (1983), that is, by replacing $\widetilde{a}_{i t}$ with a linear combination of trend or demographic variables, and appending an additive error to (12). 
We propose to estimate the aggregate analog of equation (9) instead. Define

$$
z_{i j t}=W_{i t} \ln p_{j t} .
$$

and let $e_{i t}=a_{i t}-c_{i} \delta_{t}$. Substituting (6) and (13) into (12) then gives

$$
W_{i t}=a_{i 0}+a_{i 1} t+\sum_{j=1}^{N} b_{i j} r_{j t}-\sum_{j=1}^{N} c_{j} z_{i j t}+e_{i t} .
$$

Separate from any considerations of nonstationarity or aggregation, one advantage of defining the model this way is that the errors $e_{i t}$ are by definition equal to $a_{i t}-c_{i} \delta_{t}$ and so can be directly interpreted as preference heterogeneity (taste) parameters, as in McElroy (1987) and Brown and Walker (1989). More importantly, (14) is linear in $r_{t}$ and $z_{i t}$. Nonstationarity in the variables and the errors can now be dealt with, as described in the next section.

We call the system of equations (14) for all goods $i$, the "Nonstationary Translog Demand System" (NTLOG) since it is based on demands derived from Translog utility functions, and some or all of its component variables may be nonstationary. If (14) were cointegrated for every good $i$, then the demand equations could be estimated using an error correction model. This would require that $e_{i t}$ be stationary. Lewbel (1991) found, using both UK and US data, that $\delta_{t}$ varies very little over time, with little or no trend or drift. Thus $e_{i t}$ is stationary if $a_{i t}$ is stationary. However, the analysis in Section 3 suggests that $e_{i t}$ is likely to be nonstationary (or nearly so), because the autoregressive root of $a_{i t}$ is (by theory) very close to unity, and there are likely random variations in preferences and in the income distribution over time. Therefore, tests of equation (14) should find no cointegration. In addition, even in our small system with few goods, there are now 10 regressors in each of the equations to be tested for cointegration, and the power of cointegration tests are known to reduce with the number of regressors. Based on approximate critical values of -6.5 and -67.5 , the fourth panel of Table 2 shows that the variables in (14) do not appear to be cointegrated.

Thus, both theory and empirical tests are consistent with $e_{i t}$ being an integrated or nearly integrated process. In the time series literature, it is recognized that imposing a unit root on nearly integrated processes can be desirable when the limiting distribution of estimators and test statistics are not well approximated by the normal distribution. In the present context, the unit root restriction can be justified given both the test results and the magnitude of $\nu_{t}$. Consistent with unit roots, the first differences of $W_{i t}, r_{j t}$, and $z_{i j t}$ for all goods $i$ and $j$ all appear to be $I(0)$, and thus standard tools for inference can be applied.

The above NTLOG model is designed for estimation with aggregate data, but it or some similar variant of equation (9) could be applied to cohort or household level data. At 
disaggregate levels, errors and income may well be stationary. But relative prices, which are faced by all households, will still be nonstationary, so the NTLOG will be useful with disaggregate data also.

A key feature of (13) is that it is linear in variables. Although those variables include cross terms in $z_{i j t}$, when differenced these variables all appear stationary. In contrast, Deaton and Muellbauer's (1980) Almost Ideal Demand model was designed to be nearly linear, but misses that "ideal" because of the presence of a quadratic price deflator, which includes terms like $r_{j t}^{2}$. First differences of $r_{j t}^{2}$ terms are not close to stationary. Thus, even in first differenced form, the correct limiting distribution for the AIDS model may still be nonstandard. Recognizing problems of high autocorrelation in levels, Deaton and Muellbauer report estimates from differencing the AIDS model, but assumed a standard limiting distribution for the result.

It is also of some interest to compare the nonstationary translog with the once popular but now rarely used Rotterdam model (see, e.g., Barten 1967 and Theil 1971). The Rotterdam model consisted of regressing differenced quantities on differenced prices and income. In retrospect, the Rotterdam model had the virtue of making the regressors stationary. Its shortcoming is that it is not consistent with utility maximization without imposing extreme restrictions on its coefficients, as described in the previous section. Unlike the Rotterdam model, the NTLOG is derived from a utility function that has flexible demands. Furthermore, the error terms of the Rotterdam, like the errors in the ordinary aggregate Translog and AIDS models, are appended to demands with no economic interpretation. In contrast, the error terms of the NTLOG are directly derived from heterogeneity in taste parameters and variations in the income distribution.

The NTLOG is designed to be both flexible, in the sense of Diewert (1974), and completely linear in nonstationary observables to permit differencing to stationarity. However, the Translog is a rank two demand system, with budget shares linear in log income, while empirical evidence on household level data suggests demands are quadratic and rank three. See Howe, Pollak and Wales (1979), Gorman (1981), Lewbel (1991), Blundell, Pashardes, and Weber (1995), and Banks, Blundell, and Lewbel (1997).

While demands for individual households appear to be rank three, there is evidence that aggregate demands may be adequately modeled as rank two. Lewbel (1991) shows that rank three curvature arises primarily from households at the extremes of the income distribution, and that excluding a small percentage of households in these tails results in demands that are empirically rank two. If the contribution of these small number of extreme households 
to the aggregate is small, then the aggregate will appear rank two. Also, the range of observed aggregate (per capita) income is small relative to the range of incomes that exists across households. The impact of these rank three households in the aggregate is therefore small. In our empirical application later we find that the rank two NTLOG is satisfactory for aggregate data. Nonetheless, rank three extensions of the NTLOG could be constructed, and might be desirable for future applications using disaggregate data.

\section{Estimation and Results}

Equation (13) manages full linearity, but at the cost of having some of the regressors (the $z_{i j t}$ variables) depend on $W_{i t}$, and hence those regressors could be correlated with the errors $e_{i t}$. This issue must be dealt with upon estimation. Assume we have a vector of stationary instrumental variables $s_{t}$ that are uncorrelated with the stationary difference $\triangle e_{i t}=e_{i t}-$ $e_{i t-1}$. Then

$$
E\left[s_{t}\left(\triangle W_{i t}-a_{i 1}-\sum_{j=1}^{N} b_{i j} \triangle r_{j t}+\sum_{j=1}^{N} c_{j} \triangle z_{i j t}\right)\right]=0
$$

The set of equations (15) for all goods $i$ can be stacked to yield a collection of moment conditions for the parameters, which can be estimated using standard GMM. The instruments and the differenced variables in (15) are all stationary, so the coefficients in this GMM will have the standard root- $T$ normal limiting distribution. Since these are demand equations, and the errors arise from preference heterogeneity, suitable instruments will be variables that affect the supply side of the economy.

To check sensitivity to the choice of instruments, we consider two sets of instruments. The first simply uses differences in the lags of the variables in the system: $\triangle W_{i t-2}, i=1, \ldots N-$ 1, $\triangle \ln p_{i t-2}, i=1, \ldots N, \triangle \ln M_{t-2}, \triangle z_{1 j t}, j=1,2$, the differenced log of population, a constant, and a time trend. These instruments deal with the dependence of $z$ on endogenous budget shares, but fail to control for classical simultaneity of demand with supply

The second set of instruments, which should be suitable for both these problems, consist of supply variables, like those used in, e.g., Jorgenson, Lau, and Stoker (1983). These instruments are the deflator for civilian compensation of government employees, government purchases and its deflator, imports of goods and services, wages and salaries, unit labor costs and participation rate, government transfers to individuals, unemployment, and population. These are also differenced to stationarity. Also included are a constant and a time trend. The first set of instruments has 13 variables and the second has 14, yielding a total of 39 
and 42 moment conditions respectively. It is not feasible to use both sets of instruments simultaneously, because doing so will result in too many moment conditions relative to the sample size.

A non-standard feature of our application of GMM is the following. The adding up constraint means that the condition $\sum_{i=1}^{N} e_{i t}=0$ must be satisfied. Therefore, if $\Delta e_{i t}$ were serially correlated, the dynamic structure would need to be the same for every equation, as in Berndt and Savin (1975). We first estimate the parameters with the White-Huber correction for heteroskedasticity, and then test for serial correlation in the residuals. First differencing appears to be sufficient to render $\widehat{e}_{i t}$ approximately white noise, and the Box-Ljung statistic with six lags cannot reject the null hypothesis of no serial correlation at the $5 \%$ level for equations 1 and 2, and at the 10\% level for equation 3. We also tried quasi-differencing the first differenced data to estimate a common $\mathrm{AR}(1)$ parameter for the residuals. Its estimate is numerically small and insignificant, so those results will not be reported.

For a system of $N$ consumption groups, only $N-1$ equations need to be estimated given the adding up constraint. After imposing the symmetry condition $b_{i j}=b_{j i}$, the homogeneity condition $c_{i}=\sum_{j=1}^{N} b_{i j}$, and the exact aggregation condition $\sum_{i=1}^{N} c_{i}=0$, we still have 12 parameters in a model with four goods. We first obtain unrestricted estimates of all parameters, and then restrict those $b_{i j}, i \neq j$ that are statistically insignificant to zero to improve precision of the estimates. These results are reported in Table 4. Overall, the $\chi^{2}$ test for overidentifying restrictions cannot reject the orthogonality conditions.

\subsection{Testing the Model}

We consider two additional tests of the empirical adequacy of the NTLOG model. The first is a test for stability of the coefficients (that are not statistically different from zero in the full sample). For both sets of instruments, the sup LM test of Andrews (1993) is maximized at $\pi=.2$, where $\pi T$ is the breakpoint for a sample of size $T$. The test statistic is 16.38 and 11.43 for the two sets of instruments respectively, and the $5 \%$ critical value for seven parameters is 21.07. Thus, we cannot reject the null hypothesis of parameter constancy.

The second is a general test for any omitted factors, analogous to our earlier use of equation (3) to test for the existence of any function $g$ in equation (2). Suppose the nonstationary Translog omits some variable, or some function of variables, $g_{t}$, which could be price related because of flexible regularity issues, income related due to rank considerations, or some other 
source of misspecification such as omitted dynamic or demographic effects. Then

$$
W_{i t} \equiv d_{i} g_{t}+a_{i 0}+a_{i 1} t+\sum_{j=1}^{N} b_{i j} r_{j t}-\sum_{j=1}^{N} c_{j} z_{i j t}+e_{i t}
$$

For example, $d_{i} g_{t}$ could be a component of $\alpha_{i t}$, or (16) could arise from the aggregation of demands of a potentially rank three utility function.

Analogous to how equation (2) implies equation (3), we have that if equation (16) holds for any $g_{t}$ then

$$
W_{i t} \equiv d_{i} W_{k t}+\widetilde{a}_{i 0}+\widetilde{a}_{i 1} t+\sum_{j=1}^{N} \widetilde{b}_{i j} r_{j t}-\sum_{j=1}^{N} c_{j}\left(z_{i j t}-d_{i} z_{k j t}\right)+\widetilde{e}_{i t} .
$$

Each equation (17) for $i=2, \ldots, N-1$ is linear in the observables, and so can be estimated by differencing and GMM, again using our instruments $s_{t}$. We may thereby indirectly test for the existence of any omitted factor $g_{t}$ by testing whether the coefficients $d_{i}$ are statistically significant. We may similarly test for two omitted variables by including two different budget shares as regressors in place just $W_{k t}$ in (17), analogous to using equation (5) to test for the structure of (4). A total of 27 variations of the model exist, depending on which budget shares are modeled and which are used as regressors. To conserve space, Table 5 only report results for 12 configurations. When good 4 (others) is added to the food equation, the $t$ statistic is sometimes significant at the 2-tailed $5 \%$ level, suggesting some (though not overwhelming) evidence of omitted variables. But for both sets of instruments, the $t$ - statistic on other $d_{i}$ are generally insignificant.

\subsection{Elasticities}

Aggregate quantities are given by $Q_{i t}=M_{t} W_{i t} / p_{i t}$. One can verify from (12) that the corresponding aggregate price and income elasticities are given by

$$
\begin{aligned}
& \frac{\partial \ln Q_{i t}}{\partial \ln p_{j t}}=\frac{\left(b_{i j} / W_{i t}\right)-c_{j}}{1+\sum_{k=1}^{N} c_{k} \ln p_{k t}}-1_{i j}, \\
& \frac{\partial \ln Q_{i t}}{\partial \ln M_{t}}=\frac{c_{i} / W_{i t}}{1+\sum_{k=1}^{N} c_{k} \ln p_{k t}}+1
\end{aligned}
$$

where $1_{i j}$ is the kronecker delta, which equals one if $i=j$, and zero otherwise. The constants $a_{0 i}$ are not identified when differencing as in equation (15). The elasticity formulas given in equations (18) and (19) do not make use of $a_{0 i}$, and so are identified. We present estimates 
of price and income elasticities (evaluated at the mean) in Table 5. The standard errors are calculated using the delta method.

We find that spending on energy and other goods is not price sensitive. The income elasticities for energy and for clothing are above one, while food and other goods are income inelastic. Also, according to the NTLOG estimates, a one percent increase in the price of food reduces expenditure on food by 0.68 percent, while a one percent increase in the price of clothing reduces expenditure on clothing by around two percent. These elasticities are statistically significant and are larger than most others based on time series data in the literature, which are generally estimated over a shorter sample. See e.g., Denton, Mountain and Spencer (1999) for a survey of estimates. Using the standard translog model, Jorgenson, Lau, and Stoker (1983) found a very large price elasticity for a combined food and clothing group. In results not reported, we find that estimation of the standard translog model with our data set over the same time period yields a positive own price elasticity for food, and income elasticities for food and clothing that are about double those based on the NTLOG. One cannot make inference about the statistical significance of the standard translog estimates, because the standard translog model is expressed in terms of nonstationary variables. The asymptotic normality of the NTLOG estimates, on the other hand, allows for standard inference.

The elasticities evaluated at the sample means reported in Table 6 have reasonable magnitudes and signs. An interesting implication of nonstationarity of prices is that elasticities may drift over time. This is illustrated in Figure 4, with estimates taken from INST2. The price elasticity for energy appears to change little over time and has historically been quite small. The price elasticity for food has fallen somewhat during the course of the past forty years, but the variations around the mean elasticity of -.6 are rather small. The price elasticity for clothing evaluated at the mean is -2.68 , but has increased in magnitude from about -2.2 in the beginning of the sample to -3.3 in recent years. The price elasticity for other goods seems to have increased since the mid-sixties, when these goods became a much larger share of total spending (see Figure 1). The time series of income elasticities are presented in Figure 5. A notable feature is that, not only has clothing become more price sensitive over time, but its the income elasticity has also gone up. These time variations in price and income elasticities may reflect substantial changes in the composition of these categories over time. 


\subsection{Aggregate Fixed Effect Estimates}

Our empirical analyses provide evidence that aggregate demand system errors are nonstationary. We have suggested that nonstationarity of errors could be due to aggregation of consumer's fixed effects across a slowly evolving population of consumers with heterogeneous preferences. We now provide some empirical evidence to suggest that this explanation is at least plausible. The ideal data for this exercise would be consumer level information over a long span, but detailed information on consumption of households (such as the CEX) is generally available in the form of short panels or rotating panels that do not track the same households, neither of which are suited for the estimation of individual specific effects. The best available data for our purpose appears to be the PSID, which tracks households' food consumption and income since 1968.

We begin by estimating the food demand equation

$$
w_{h t}=a_{h}+\gamma z_{h t}+\delta_{t}+\beta_{t} \log m_{h t}+\epsilon_{h t},
$$

where $z_{h t}$ is age and family size to control for observed sources of heterogeneity, and $a_{h}$ is the fixed effect for each household $h$. The regression includes year dummies both additively and interacted with log income to obtain the time varying coefficients $\delta_{t}$ and $\beta_{t}$. This is equivalent to estimating a separate Engel curve for each time period, so this analysis does not require measuring prices or specifying how prices affect food demands at the household level.

We only consider male headed households with at least 10 observations over our estimation sample of 1974 to 1992 , and who are between age 25 and 55. ${ }^{9}$ By performing fixed effect estimation, we can obtain $\widehat{a}_{h}$ for 1308 households.

Given a sample, we cannot observe households entering or leaving the true population of households $\mathcal{H}_{t}$, so we proxy changes in the population by changes in subpopulations, defined by age. As a first check, we aggregate the estimated fixed effect corresponding to the 147 households that are in the sample all 17 years. In this first example there is, by construction, no change over time in the composition of this subpopulation of households, so the aggregate is constant over time (see Table 7). This first example corresponds to the extreme case of $\nu_{t}=1$ and $\eta_{i t}=0$ in section 3 . We then construct three estimated aggregate fixed effects, based on different subpopulations. The first averages the fixed effect across those households

\footnotetext{
${ }^{9}$ Food is the sum of food consumed at home plus food consumed outside of home. Food data were not collected in 1973, 1987 and 1988. The SEO sample was excluded from the analysis. Households who reported zero income and/or consumption are dropped.
} 
that are between ages 30 and 50 in each time period, the second between ages 30 and 40, and the third between ages 40 and 50. In all three cases, the sample size changes over time both as the size of the subpopulation changes and as households drop in and out of the interviews. The average number of observations used in the aggregations are 803, 505 and 337 respectively, with standard deviations of 147, 243, and 146, respectively.

The estimates reported in Table 7 suggest strong trends in the resulting aggregate fixed effects, consistent with our conjecture that these series can be highly persistent. The first order autoregressive parameter is estimated to be near unity in every case. ${ }^{10}$

This simple exercise is subject to many caveats due to data limitations. For example, there is likely to be more period to period change in the survey respondents than the population at large. Nonetheless, the results suggest that aggregation of demand equation fixed effects over a slowly evolving heterogeneous population could be a plausible cause of apparent nonstationarity of errors in aggregate demand systems.

\section{Conclusions}

Price and income elasticities are important statistics which characterize consumers behavior and are fundamental to the evaluation of tax policies and welfare programs. Demand systems provide a conceptually coherent framework for estimating these elasticities. Utility maximization requires any reasonable specification of demand systems to be nonlinear in relative prices, and relative prices themselves are nonstationary.

Very few techniques exist for estimation of structural nonlinear models with nonstationary data. The vast majority of existing empirical demand system studies, with either household or more aggregate level data, simply ignore this problem, treating the data as if it were stationary. The few empirical studies that do consider price nonstationarity assume linearity by, for example, estimating an Almost Ideal model while ignoring its nonlinear component, which is a quadratic price index.

To deal with price nonstationarity, we propose a reformulation of the utility derived Translog model that can be written in a linear form (albeit with endogeneity in the regressors caused by interacting prices with budget shares), thereby avoiding the severe constraints of ordinary utility derived linear demand models, while preserving sufficient linear structure to deal with nonstationarity. Our NTLOG model provides a solution to the empirical problem,

\footnotetext{
${ }^{10}$ Formal tests of nonstationarity or unit roots in the data in Table 7 are not practical, because the number of time periods is very short, no data are available in some years, and ordinary tests would fail to account for estimation errors in the generation of this data.
} 
which exists at both the household and aggregate level, of demand system estimation with nonstationary relative prices.

In addition to handling nonstationarity of relative prices, our NTLOG model can also cope with possible nonstationarity of demand systems errors, a feature commonly found in models using aggregate data. We show theoretically that nonstationarity of demand system errors could arise from aggregation across heterogeneous consumers in a slowly changing population, and we provide some empirical evidence for this effect based on a panel of household demands for food. Other possible sources of nonstationarity could be omitted variables, omitted dynamics, or aggregation across goods as in Lewbel (1996). We provide some empirical evidence against the omitted variables explanation.

We estimate this NTLOG model using aggregate U.S. data over the sample 1954-1998. The model is subjected to and passes a variety of specification tests. Estimates of the model parameters and elasticities are also reported, and are found to be economically plausible. Unlike other demand system estimates in the literature, given nonstationary data and nonstationary errors, these NTLOG estimates have root- $T$ asymptotically normal distributions and so allow for standard inference. 
Table 1: Tests for Nonstationarity of Prices and Total Expenditure

\begin{tabular}{|c|c|c|c|c|c|c|}
\hline Series & $D F G L S_{\tau}$ & $M Z_{\alpha \tau}^{G L S}$ & Lags & $D F G L S_{\mu}$ & $M Z_{\alpha \mu}^{G L S}$ & Lags \\
\hline & \multicolumn{3}{|c|}{ Levels } & \multicolumn{3}{|c|}{ First Differences } \\
\hline $\log \left(p_{1}\right)$ & -1.541 & -5.506 & 3 & -3.153 & -17.191 & 2 \\
\hline $\log \left(p_{2}\right)$ & -1.268 & -4.901 & 3 & -3.813 & -25.618 & 2 \\
\hline $\log \left(p_{3}\right)$ & -1.107 & -5.574 & 4 & -2.613 & -11.675 & 4 \\
\hline $\log \left(p_{4}\right)$ & -1.442 & -4.650 & 3 & -2.044 & -8.031 & 2 \\
\hline $\log \left(r_{1}\right)$ & $\overline{-2.384}$ & -11.371 & 1 & $\overline{-2.509}$ & -11.856 & 3 \\
\hline $\operatorname{lor}\left(r_{2}\right)$ & -1.842 & -9.818 & 4 & -4.525 & -32.102 & 2 \\
\hline $\log \left(r_{3}\right)$ & -0.975 & -2.408 & 2 & -1.568 & -5.173 & 4 \\
\hline $\log \left(r_{4}\right)$ & -0.924 & -2.141 & 2 & -4.580 & -33.948 & 2 \\
\hline $\log \left(p_{1} / p_{2}\right)$ & $\overline{-1.624}$ & -7.065 & 4 & $\overline{-5.813}$ & -56.045 & 2 \\
\hline $\log \left(p_{1} / p_{3}\right)$ & -1.370 & -4.183 & 2 & -4.620 & -36.045 & 3 \\
\hline $\log \left(p_{1} / p_{4}\right)$ & -1.200 & -3.713 & 3 & -3.944 & -25.392 & 3 \\
\hline $\log \left(p_{2} / p_{3}\right)$ & -1.182 & -2.903 & 1 & -3.757 & -24.921 & 4 \\
\hline $\log \left(p_{2} / p_{4}\right)$ & -0.732 & -2.091 & 1 & -6.030 & -62.858 & 4 \\
\hline $\log \left(p_{3} / 4\right)$ & -0.773 & -2.028 & 4 & -3.594 & -17.646 & 4 \\
\hline $\log (\mathrm{M})$ & -1.284 & -3.937 & 3 & -1.958 & -7.532 & 4 \\
\hline$W_{1}$ & -1.707 & -5.887 & 1 & -4.321 & -30.873 & 4 \\
\hline$W_{2}$ & -0.953 & -2.237 & 0 & -6.644 & -68.654 & 2 \\
\hline$W_{3}$ & -1.701 & -6.441 & 0 & -5.944 & -58.423 & 3 \\
\hline$W_{4}$ & 0.058 & 0.2149 & 0 & -2.551 & -8.446 & 4 \\
\hline$w_{1} \log \left(p_{1}\right)$ & -.756 & -5.204 & 3 & -2.060 & -8.524 & 2 \\
\hline$w_{1} \log \left(p_{2}\right)$ & -.664 & -3.189 & 3 & -3.647 & -26.940 & 4 \\
\hline$w_{1} \log \left(p_{3}\right)$ & .179 & -.085 & 2 & -2.339 & -10.237 & 4 \\
\hline$w_{1} \log \left(p_{4}\right)$ & -.878 & -5.478 & 3 & -3.726 & -21.141 & 2 \\
\hline$w_{2} \log \left(p_{1}\right)$ & -.858 & -1.662 & 1 & -4.522 & -33.241 & 3 \\
\hline$w_{2} \log \left(p_{2}\right)$ & -1.168 & -4.446 & 3 & -2.804 & -12.830 & 3 \\
\hline$w_{2} \log \left(p_{3}\right)$ & -.994 & -4.832 & 4 & -3.158 & -12.997 & 4 \\
\hline$w_{2} \log \left(p_{4}\right)$ & -.739 & -1.057 & 1 & -2.258 & -7.651 & 4 \\
\hline$w_{3} \log \left(p_{1}\right)$ & -.458 & -1.236 & 1 & -4.564 & -28.905 & 3 \\
\hline$w_{3} \log \left(p_{2}\right)$ & -.7751 & -2.652 & 2 & -4.172 & -29.847 & 2 \\
\hline$w_{3} \log \left(p_{3}\right)$ & -.169 & -.813 & 2 & -4.752 & -35.906 & 3 \\
\hline$w_{3} \log \left(p_{4}\right)$ & -.880 & -2968 & 2 & -4.012 & -19.959 & 3 \\
\hline$w_{4} \log \left(p_{1}\right)$ & -.946 & -2.344 & 3 & -2.441 & -9.365 & 3 \\
\hline$w_{4} \log \left(p_{2}\right)$ & -1.042 & -2.278 & 3 & -2.927 & -15.130 & 4 \\
\hline$w_{4} \log \left(p_{3}\right)$ & -1.046 & -3.110 & 3 & -2.743 & -10.189 & 4 \\
\hline$w_{4} \log \left(p_{4}\right)$ & -1.175 & -3.110 & 4 & -.947 & -1.518 & 4 \\
\hline
\end{tabular}

The $5 \%$ critical values for the $D F G L S_{\tau}$ and the $M Z_{\alpha \tau}^{G L S}$ (which include a constant and a linear time trend) are -2.9 and -19.1 respectively. The critical values for $D F G L S_{\mu} M Z_{\alpha \mu}^{G L S}$ (which include a constant) are -1.9 and -8.1 respectively. 
Table 2: Tests for the Null Hypothesis of No-Cointegration

Equation 1: $W_{i t}=a_{0 i}+a_{1 i} t+\sum_{j=1}^{N} b_{i j} r_{j t}+e_{i t}$

\begin{tabular}{|c|c|c|c|}
\hline Good & DF & $M Z_{\alpha}$ & Lags \\
\hline 1 & -2.835 & -11.512 & 0 \\
2 & -2.446 & -13.545 & 1 \\
3 & -4.885 & -31.804 & 0 \\
4 & -2.665 & -10.673 & 0 \\
\hline CV & -4.49 & -37.7 & \\
\hline
\end{tabular}

Equation 2: $W_{i t}=a_{0 i}+a_{1 i} t+b_{i}^{\prime} r_{t}+c_{i} \log \left(M_{t} / P_{t}^{*}\right)+e_{i t}$

\begin{tabular}{|c|c|c|c|}
\hline Good & DF & $M Z_{\alpha}$ & Lags \\
\hline 1 & -3.139 & -18.098 & 0 \\
2 & -3.226 & -20.042 & 1 \\
3 & -5.210 & -30.300 & 0 \\
4 & -3.732 & -14.835 & 0 \\
\hline CV & -4.74 & -42.5 & \\
\hline
\end{tabular}

Equation 4: $W_{i t}=a_{0 i}+a_{1 i} t+b_{i}^{\prime} r_{t}+c_{1 i} \log \left(M_{t} / P_{t}^{*}\right)+c_{2 i}\left[\log \left(M_{t} / P_{t}^{*}\right)\right]^{2}+e_{i t}$

\begin{tabular}{|c|c|c|c|}
\hline Good & DF & $M Z_{\alpha}$ & Lags \\
\hline 1 & -3.568 & -22.125 & 0 \\
2 & -2.608 & -13.831 & 1 \\
3 & -5.426 & -43.275 & 0 \\
4 & -2.242 & -9.785 & 0 \\
\hline CV & -5.04 & -47.5 & \\
\hline
\end{tabular}

Equation $18 W_{i t}=a_{0 i}+a_{1 i} t+\sum_{j=1}^{N} b_{i j} r_{j t}+\sum_{j=1}^{N} c_{j} z_{i j t}+e_{i t}$

\begin{tabular}{|c|c|c|c|}
\hline Good & DF & $M Z_{\alpha}$ & Lags \\
\hline 1 & -4.356 & -28.923 & 0 \\
2 & -4.430 & -35.425 & 1 \\
3 & -6.029 & -50.875 & 0 \\
4 & -4.344 & -32.421 & 0 \\
\hline CV & -6.5 & -67.5 & \\
\hline
\end{tabular}


Table 3: Tests for the Null Hypothesis of No-Cointegration:

Equation 3:

\begin{tabular}{|c|c|c|c|c|}
\hline Good $i$ & Good $j$ & $\mathrm{DF}$ & $M Z_{\alpha}$ & Lags \\
\hline 2 & 1 & -2.450 & -13.525 & 1 \\
\hline 3 & 1 & -4.883 & -32.419 & 0 \\
\hline 4 & 1 & -2.317 & -9.802 & 0 \\
\hline 1 & 2 & -2.881 & -11.895 & 0 \\
\hline 3 & 2 & -5.456 & -37.449 & 0 \\
\hline 4 & 2 & -4.180 & -20.909 & 0 \\
\hline 1 & 3 & -2.825 & -12.175 & 0 \\
\hline 2 & 3 & -3.012 & -17.663 & 1 \\
\hline 4 & 3 & -3.524 & -23.658 & 0 \\
\hline 1 & 4 & -2.487 & -10.667 & 0 \\
\hline 2 & 4 & -3.724 & -21.577 & 1 \\
\hline 3 & 4 & -5.479 & -42.895 & 0 \\
\hline $\mathrm{CV}$ & & -4.74 & -42.5 & \\
\hline
\end{tabular}

Equation 5:

\begin{tabular}{|c|c|c|c|c|}
\hline Good $i$ & Goods $j k$ & \multicolumn{2}{|c|}{$W_{i t}=\widetilde{a}_{0 i}+\widetilde{a}_{1 i}+b_{i}^{\prime} r_{t}+\widetilde{c}_{i j} W_{j t}+\widetilde{c}_{i k} W_{k t} e_{i t}, j, k \neq i$} & Inace \\
\hline 1 & 23 & 2851 & חمח2 12 & 0 \\
\hline & & & 104 & \\
\hline 1 & 2,4 & -2.411 & $-10.48 r$ & 0 \\
\hline 1 & 3,4 & -2.127 & -7.509 & 1 \\
\hline 2 & 1,3 & -2.997 & -17.252 & 1 \\
\hline 2 & 1,4 & -3.722 & -22.032 & 1 \\
\hline 2 & 3,4 & -3.558 & -22.159 & 1 \\
\hline 3 & 1,4 & -5.404 & -41.440 & 0 \\
\hline 3 & 1,2 & -5.438 & -37.798 & 0 \\
\hline 3 & 2,4 & -5.050 & -38.951 & 0 \\
\hline 4 & 1,2 & -3.825 & -19.744 & 0 \\
\hline 4 & 1,3 & -2.889 & -18.44 & 1 \\
\hline 4 & 2,3 & -3.660 & -21.983 & 0 \\
\hline $\mathrm{CV}$ & & -5.04 & -47.5 & \\
\hline
\end{tabular}


Table 4: Restricted and Unrestricted Estimates of the Parameters by GMM

\begin{tabular}{|c|c|c|c|c|}
\hline & \multicolumn{2}{|c|}{ INST1 } & \multicolumn{2}{c|}{ INST2 } \\
\hline & Unrestricted & Restricted & Unestricted & Restricted \\
\hline$b_{11}$ & 0.1186 & 0.0838 & 0.1665 & 0.0988 \\
se & 0.1077 & 0.0886 & 0.1086 & 0.0883 \\
\hline$b_{12}$ & 0.0020 & 0.0000 & -0.0062 & 0.0000 \\
se & 0.0563 & 0.0000 & 0.0482 & 0.0000 \\
\hline$b_{13}$ & -0.0484 & 0.0000 & -0.0602 & 0.0000 \\
se & 0.0403 & 0.0000 & 0.0483 & 0.0000 \\
\hline$b_{22}$ & 0.1661 & 0.1206 & 0.1408 & 0.1048 \\
se & 0.0487 & 0.0410 & 0.0509 & 0.0390 \\
\hline$b_{23}$ & -0.0373 & 0.0000 & -0.0438 & 0.0000 \\
se & 0.0287 & 0.0000 & 0.0310 & 0.0000 \\
\hline$b_{24}$ & -0.1672 & -0.1835 & -0.1474 & -0.1768 \\
se & 0.0623 & 0.0532 & 0.0621 & 0.0466 \\
\hline$b_{33}$ & -0.0617 & -0.0715 & -0.1121 & -0.1387 \\
se & 0.0361 & 0.0392 & 0.0407 & 0.0415 \\
\hline$b_{34}$ & -0.0191 & 0.0000 & -0.0181 & 0.0000 \\
se & 0.0427 & 0.0000 & 0.0533 & 0.0000 \\
\hline$b_{44}$ & 0.4851 & 0.3153 & 0.5064 & 0.4075 \\
se & 0.1214 & 0.1230 & 0.1475 & 0.1350 \\
\hline$a_{11}$ & -0.0009 & -0.0008 & -0.0008 & -0.0007 \\
se & 0.0003 & 0.0002 & 0.0003 & 0.0002 \\
\hline$a_{12}$ & 0.0001 & 0.0000 & -0.0001 & 0.0000 \\
se & 0.0002 & 0.0000 & 0.0002 & 0.0000 \\
\hline$a_{13}$ & -0.0007 & -0.0005 & -0.0010 & -0.0008 \\
se & 0.0002 & 0.0002 & 0.0002 & 0.0002 \\
\hline$\chi^{2}$ & 25.095 & 32.360 & 25.924 & 30.323 \\
$\mathrm{~d} . f$. & 27 & 332 & 30 & 35 \\
\hline \hline & & & & \\
\hline
\end{tabular}


Table 5a: Specification Tests with INST1:

\begin{tabular}{|c|c|c|c|}
\hline$(\mathrm{i}, \mathrm{j}, \mathrm{k})$ & $t_{i}$ & $t_{j}$ & $t_{k}$ \\
\hline$(2,1,1)$ & -0.6336 & -0.3359 & -0.3005 \\
\hline$(3,1,1)$ & -0.7389 & -0.1753 & -0.2321 \\
\hline$(4,1,1)$ & -2.2732 & -0.4706 & 0.3154 \\
\hline$(2,3,4)$ & -0.3955 & -1.9064 & -0.3559 \\
\hline$(3,1,4)$ & -0.6823 & -0.1775 & -0.5276 \\
\hline$(4,1,4)$ & -2.1087 & -0.4602 & -0.0459 \\
\hline$(3,4,1)$ & -0.6355 & -0.7701 & -0.0733 \\
\hline$(3,4,2)$ & -0.6164 & -0.7175 & -0.1656 \\
\hline$(3,4,4)$ & -0.5854 & -0.6251 & -0.3532 \\
\hline$(4,3,1)$ & -2.2817 & -1.7406 & 0.3635 \\
\hline$(4,3,2)$ & -2.2068 & -1.7463 & 0.2535 \\
\hline$(4,3,4)$ & -2.1489 & -1.8058 & 0.0476 \\
\hline
\end{tabular}

The first column denotes the variables being added to the equation for Good 1, 2, and 3 respectively. The next three columns are the $t$ statistic on the variable being added.

Table 5b: Specification Tests with INST2:

\begin{tabular}{|c|c|c|c|}
\hline$(\mathrm{i}, \mathrm{j}, \mathrm{k})$ & $t_{i}$ & $t_{j}$ & $t_{k}$ \\
\hline$(2,1,1)$ & -0.9181 & 0.5734 & 0.8393 \\
\hline$(3,1,1)$ & -1.4878 & 0.6800 & 0.9548 \\
\hline$(4,1,1)$ & -1.9244 & 0.1801 & 0.9574 \\
\hline$(2,3,4)$ & -1.2099 & 0.2463 & 0.3557 \\
\hline$(3,1,4)$ & -1.4857 & 0.6412 & 0.6393 \\
\hline$(4,1,4)$ & -1.8274 & 0.1964 & 0.6944 \\
\hline$(3,4,1)$ & -1.0192 & -2.2839 & 0.6290 \\
\hline$(3,4,2)$ & -1.0342 & -2.1522 & 0.4570 \\
\hline$(3,4,4)$ & -0.9126 & -2.2949 & 0.3867 \\
\hline$(4,3,1)$ & -2.0192 & -0.1576 & 0.7604 \\
\hline$(4,3,2)$ & -2.0149 & -0.1076 & 0.7502 \\
\hline$(4,3,4)$ & -1.9207 & -0.1403 & 0.5289 \\
\hline
\end{tabular}

The first column denotes the variables being added to the equation for Good 1, 2, and 3 respectively. The next three columns are the $t$ statistic on the variable being added. 
Table 6a: Estimates of Price and Income Elasticities for the NTLOG using INST1

\begin{tabular}{|c|c|c|c|c|c|}
\hline & \multicolumn{4}{|c|}{ Price } & Income \\
\hline Good & 1 & 2 & 3 & 4 & \\
\hline 1 (food) & -0.6808 & 0.0638 & 0.0724 & -0.2682 & 0.8128 \\
se & 0.3847 & 0.0734 & 0.0722 & 0.2995 & 0.6090 \\
\hline 2 (energy) & -0.0438 & -0.1661 & 0.0724 & -1.2644 & 1.4019 \\
se & 0.1424 & 0.9802 & 0.0722 & 1.2932 & 0.4626 \\
\hline 3 (clothing) & -0.0438 & 0.0638 & -1.8580 & -0.0924 & 1.9305 \\
se & 0.1424 & 0.0734 & 0.8553 & 0.0901 & 0.9275 \\
\hline 4 (others) & -0.1326 & -0.3379 & 0.0724 & -0.4024 & 0.8004 \\
se & 0.1361 & 0.3798 & 0.0722 & 0.3885 & 0.1946 \\
\hline
\end{tabular}

Table 6b: Estimates of Price and Income Elasticities for the NTLOG using INST2

\begin{tabular}{|c|c|c|c|c|c|}
\hline & \multicolumn{4}{|c|}{ Price } & Income \\
\hline Good & 1 & 2 & 3 & 4 & \\
\hline 1 (food) & -0.6068 & 0.0739 & 0.1423 & -0.4368 & 0.8274 \\
& 0.3803 & 0.0646 & 0.0987 & 0.2507 & 0.4359 \\
\hline 2 (energy) & -0.0404 & -0.2482 & 0.1423 & -1.3193 & 1.4655 \\
& 0.1019 & 0.6554 & 0.0987 & 0.9694 & 0.4069 \\
\hline 3 (clothing) & -0.0404 & 0.0739 & -2.6858 & -0.1759 & 2.8282 \\
& 0.1019 & 0.0646 & 1.1687 & 0.1211 & 1.2674 \\
\hline 4 (others) & -0.1722 & -0.3180 & 0.1423 & -0.2724 & 0.6202 \\
& 0.1486 & 0.2576 & 0.0987 & 0.3949 & 0.2615 \\
\hline
\end{tabular}


Table 7: Estimated Aggregate Fixed Effect

\begin{tabular}{|c|cccc|}
\hline Year & Balanced & Age & Age & Age \\
& Panel & $30-50$ & $30-40$ & $40-50$ \\
\hline 74 & .0757 & .1915 & .1176 & .3239 \\
75 & .0757 & .1755 & .1019 & .2938 \\
76 & .0757 & .1510 & .0731 & .2775 \\
77 & .0757 & .1286 & .0505 & .2566 \\
78 & .0757 & .1083 & .0265 & .2487 \\
79 & .0757 & .0806 & .0010 & .2243 \\
80 & .0757 & .0555 & -.0189 & .2029 \\
81 & .0757 & .0364 & -.0301 & .1729 \\
82 & .0757 & .0171 & -.0444 & .1489 \\
83 & .0757 & -.0082 & -.0690 & .1312 \\
84 & .0757 & -.0301 & -.0874 & .1003 \\
85 & .0757 & -.0478 & -.1092 & .0892 \\
86 & .0757 & -.0607 & -.1270 & .0699 \\
87 & .0757 & -.0699 & -.1427 & .0473 \\
90 & .0757 & -.0914 & -.1894 & -.0192 \\
91 & .0757 & -.0955 & -.1999 & -.0335 \\
92 & .0757 & -.1011 & -.2180 & -.0526 \\
\hline AR(1) & & .9545 & .9945 & 1.015 \\
\hline
\end{tabular}

The first column is the fixed effect aggregated over a fixed set of households. The remaining columns are based on aggregation over household heads in each year that are between age 30 and 50,30 and 40,40 and 50 respectively. The estimated individual fixed effects are from estimates of the household level food demand equation (20) using the fixed effect estimator as implemented in Stata. 


\section{Data Sources}

The data are from the US National Income and Product Accounts, obtained via Citibase. The sample period is 1954Q1-1998Q4. In citibase mnemonics, M=GC-GCD. Nominal expenditure on the four groups are:

1. GCFO (food),

2. GCNF+GCNG+GCST+GCSHO (energy),

3. GCNC (clothing),

4. others $=$ M-food-energy-clothing.

Price indices are obtained by dividing nominal by real expenditures in these groups. Following many other authors (e.g., Campbell and Mankiw 1990), data from before the mid 1950s are excluded to avoid the effects of both the Korean war and of measurement errors in the first few years of data collection.

In Citibase, the second set of instruments are GGE, GDGE, GGCGE, GIMQ, GW, GMPT, GPOP, LBLCPU, LHUR, and LHP16. We take logs of the first six of these variables before first differencing them.

For Table 7, household level data from 1974-1992 are taken from the Panel Study of Income Dynamics, excluding the SEO sample. We use observations with male household heads that are between age 25 and 55, and have no missing data on age, sex, marital status, number of children, and income. Income is defined as the sum of earned and transfer income by the husband, wife, and other family members. Food is defined as food consumed at home and outside the home. Consumption data are not available for 1973, 1987, and 1988. A total of 17,568 observations over 17 years were used in the fixed effect estimation. 


\section{References}

Adda, J. and Robin, J. (1996), Aggregation of Nonstationary Demand Systems, CRESTINSEE WP 9634.

Andrews, D. W. K. (1993), Tests for Parameter Instability and Structural Change with Unknown Change Point, Econometrica 61, 821-856.

Attfield, C. (1997), Estimating a Cointegrated Demand System, European Economic Review 41, 61-73.

Banks, J., Blundell, R. W. and Lewbel, A. (1997), Quadratic Engel Curves and Consumer Demand, Review of Economics and Statistics 79:4, 527-539.

Barten, A. (1969), Maximum Likelihood Estimation of a Complete System of Demand Equations, European Economic Review 1, 7-73.

Barten, A. P. (1967), Evidence on the Slutsky Conditions for Demand ¿Equations, Review of Economics and Statistics 49, 77-84.

Berndt, E. R. and Savin, N. E. (1995), Estimation and Hypothesis Testing in Singular Equation Systems with Autoregressive Disturbances, Econometrica 43:5, 937-958.

Blundell, R. W., Pashardes, P. and Weber, G. (1993), What Do We Learn About Consumer Demand Patterns from Micro Data?, American Economic Reviwe 83, 570-597.

Brown, B. W. and Walker, M. B. (1989), The Random Utility Hypothesis and Inference in Demand Systems, Econometrica 57, 815-829.

Deaton, A. (1975), Models and Projections of Demand in Post-War Britain, Chapman and Hall, London.

Deaton, A. S. and Muellbauer, J. (1980), An Almost Ideal Demand System, American Economic Review 70, 312-326.

Denton, F., Mountain, D. and Spencer, B. (1999), Age, Trend, and Cohort Effects in a Macro Model of Canadian Expenditure Patterns, Journal of Business and Economic Statistics 17:4, 430-443.

Diewert, W. E. and Wales, T. J. (1987)a, Flexible Function Forms and Global Curvature Conditions, Econometrica 55, 43-68.

Diewert, W. E. and Wales, T. J. (1987)b, Flexible Functional Forms and Global Curvature Conditions, Econometrica 55, 43-68.

Elliott, G., Rothenberg, T. J. and Stock, J. H. (1996), Efficient Tests for an Autoregressive Unit Root, Econometrica 64, 813-836.

Hamilton, J. D. (1994), Time Series Analysis, Princeton University Press, Princeton, N.J.

Jorgenson, D. W., Lau, L. J. and Stoker, T. M. (1982), The Transendental Logarithmic Model of Aggregate Consumer Behavior, in R. Basmann and G. Rhodes (eds), Advances in Econometrics, Volume 11, JAI Press, Connecticut. 
Lewbel, A. (1987), Fractional Demand Systems, Journal of Econometrics 36, 311-337.

Lewbel, A. (1991), The Rank of Demand Systems: Theory and Nonparameteric Estimation, Econometrica 59, 711-730.

Lewbel, A. (1996), Aggregation Without Separability: A Generalized Composite Commodity Theorem, American Economic Review 86, 524-543.

Lewbel, A. (1996b), Large Demand Systems and Nonstationary Prices: Income and Price Elasticities for Many US Goods, mimeo Brandeis University.

Mcelroy, M. B. (1987), Additive General Error Models for Production Costs and Derived Demand or Share Equations, Journal of Political Economy 95, 737-757.

Moschini, G. (1999), Imposing Local Curvature Conditions in Flexible Demand Systems, Journal of Business and Economic Statistics 17:4, 487-490.

Ng, S. (1993), Essays in Time Series and Econometrics, Princeton University Doctoral Dissertation.

Ng, S. (1995), Testing for Homogeneity in Demand Systems when the Regressors are NonStationary, Journal of Applied Econometrics 10, 147-163.

Ng, S. and Perron, P. (2001), Lag Length Selection and the Construction of Unit Root Tests with Good Size and Power, Econometrica 69:6, 1519-1554.

Ogaki, M. (1992), Engel's Law and Cointegration, Journal of Political Economy 100, 10271046.

Perron, P. and Ng, S. (1996), Useful Modifications to Unit Root Tests with Dependent Errors and their Local Asymptotic Properties, Review of Economic Studies 63, 435-465.

Pollak, R. A. and Wales, T. J. (1969), Comparison of the Quadratic Expendtiure System and Tranlsog Demand Systems with Alternative Specifications of Demographic Effects, Econometrica 78, 575-612.

Said, S. E. and Dickey, D. A. (1984), Testing for Unit Roots in Autoregressive-Moving Average Models of Unknown Order, Biometrika 71, 599-607.

Stock, J. H. (1994), Unit Roots, Structural Breaks and Trends, Handbook of Econometrics, Vol. 4, pp. 2740-2831.

Stoker, T. (1986), Aggregation, Efficiency, and Cross-Section Regressions, Econometrica 54, 171-188.

Theil, H. (1971), Principles of Econometrics, John Wiley and Sons, New York.

Watson, M. W. (1994), Vector Autoregressions and Cointegration, Handbook of Econometrics, Vol. 4, pp. 2844-2910. 
Figure 1: Log Prices

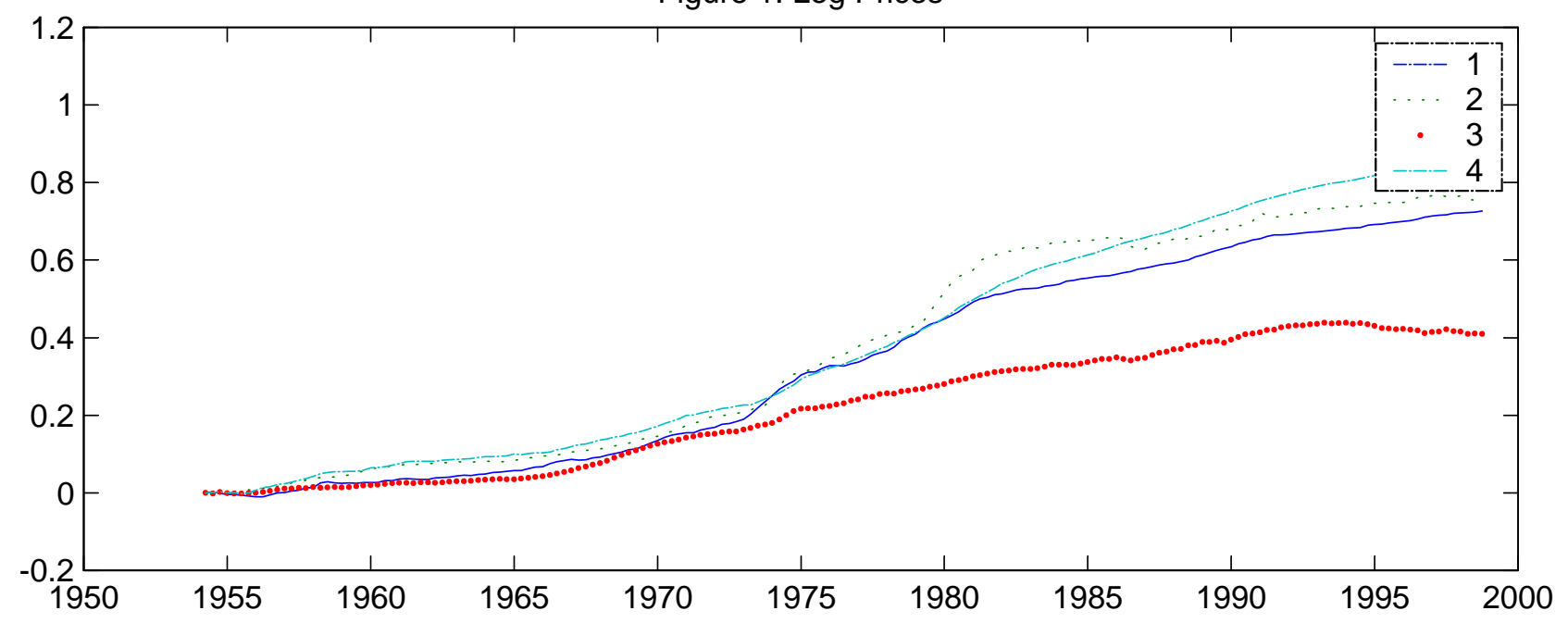

Figure 2: Log Normalized Prices ( $r$ )

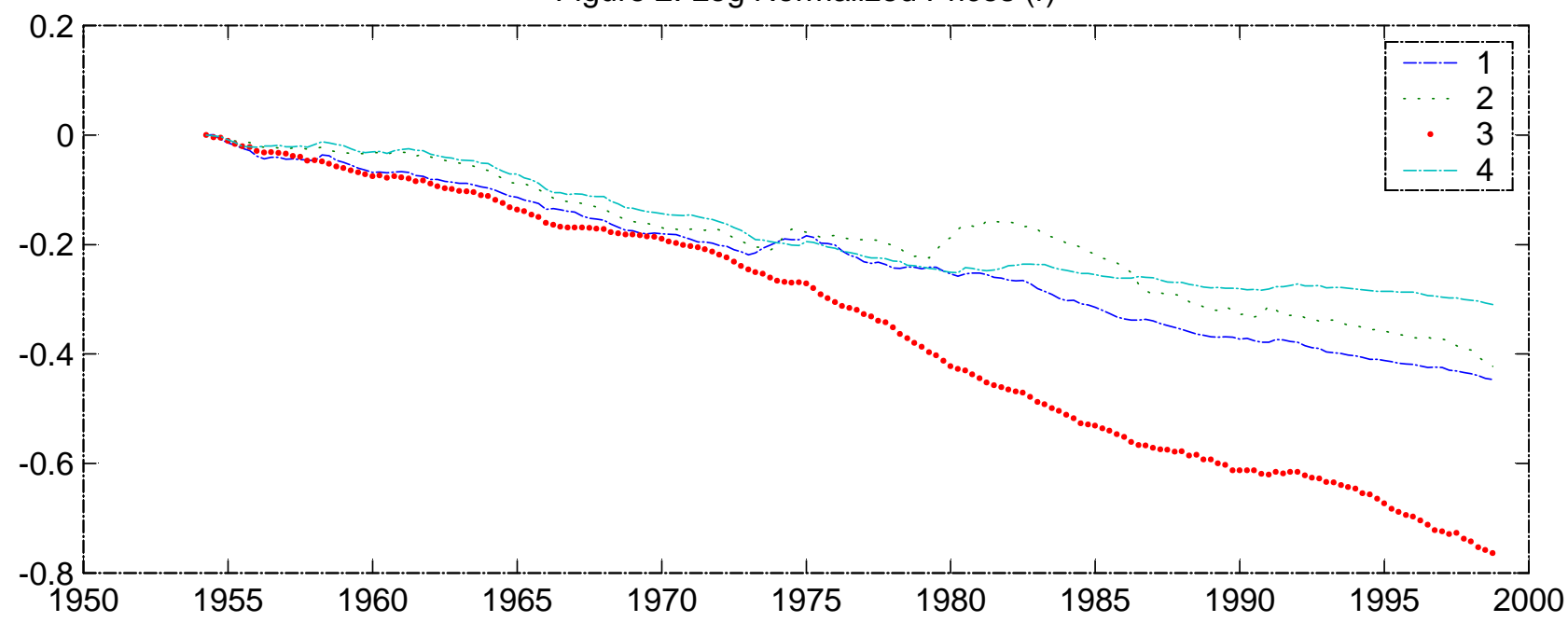

Figure 3: Shares

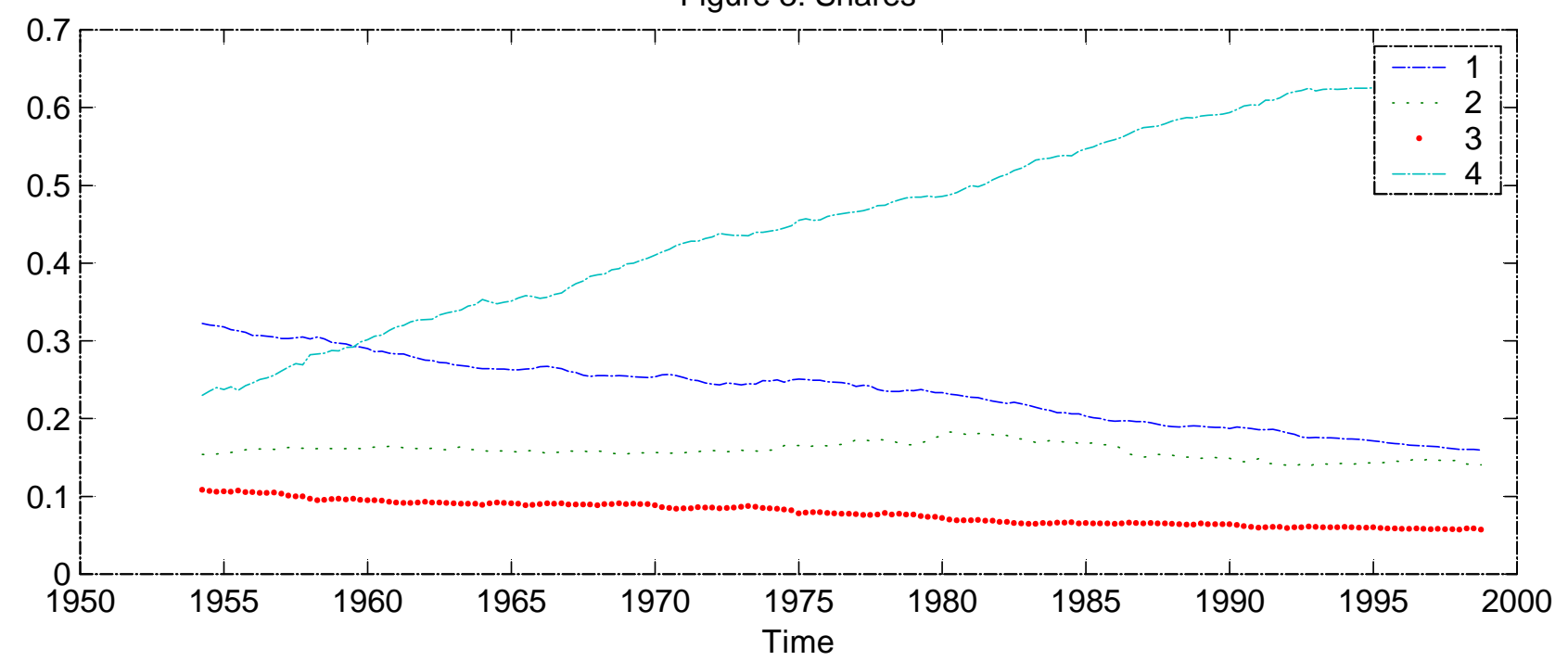


Figure 4: Own Price Elasticities

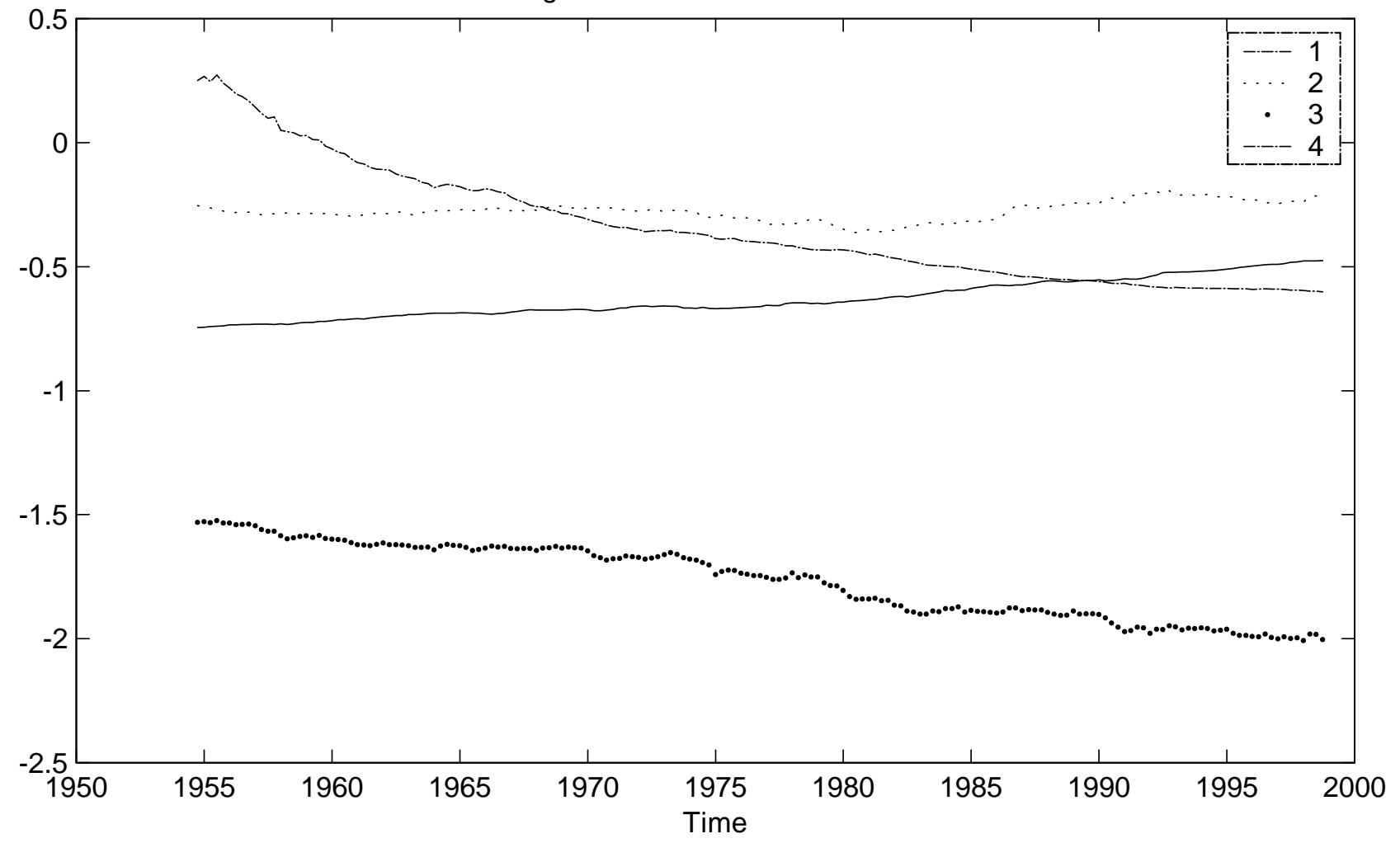

Figure 5: Income Elasticities

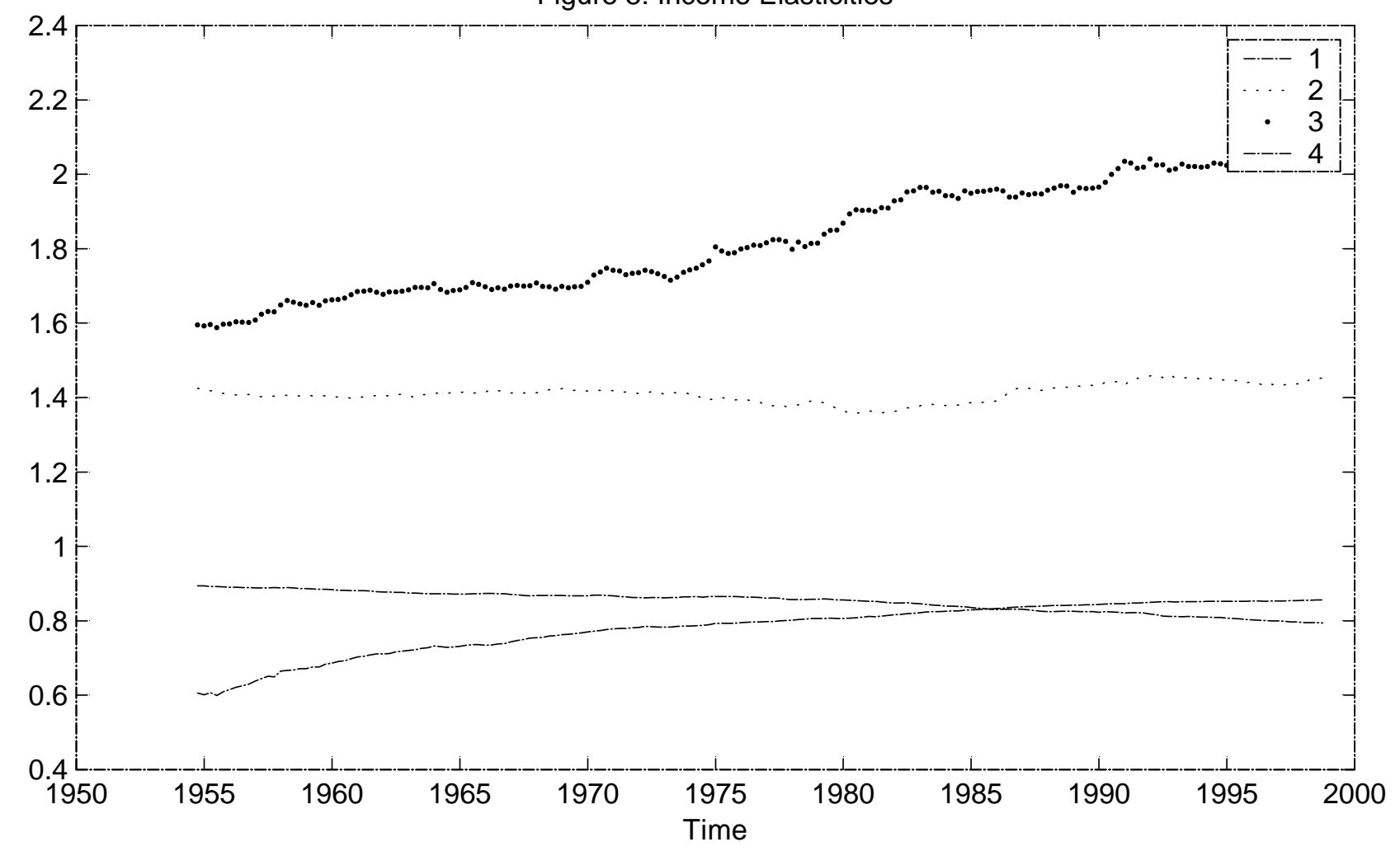

